\title{
Alcohol use in pregnancy, craniofacial features, and fetal growth
}

Agnes Rostand, Monique Kaminski, Nathalie Lelong, Philippe Dehaene, Isabelle Delestret, Catherine Klein-Bertrand, Denis Querleu, Gilles Crepin

\begin{abstract}
Study objective-The aim was to study the relationship between the level of alcohol consumption in pregnancy and craniofacial characteristics of the neonate.

Design-This was a prospective survey of a sample of pregnant women, stratified on prepregnancy level of alcohol consumption.

Setting - The study was carried out at the public antenatal clinic of Roubaix maternity hospital.

Participants-During an eight month period, 684 women ( $89 \%$ of those eligible) were interviewed in a standardised way at their first antenatal clinic visit. Of these, all who were suspected of being alcoholic or heavy drinkers (at least 21 drinks per week) were selected for follow up, as was a subsample of light (0-6 drinks per week) and moderate (7-20 drinks per week) drinkers. Of 347 women selected in this way, 202 had their infants assessed by a standardised morphological examination.
\end{abstract}

Measurements and and main resultsSuggestive craniofacial characteristics of the infants, present either in isolation or in association with growth retardation ("fetal alcohol effects"), were compared in relation to maternal alcohol consumption (alcoholic $12 \%$; heavy drinking $24 \%$; moderate drinking $28 \%$; light drinking $36 \%$ ). No differences were found between light and moderate drinkers. Infants born to alcoholics had a greater number of craniofacial characteristics and the proportion with features compatible with fetal alcohol effects was higher. There was a similar trend for infants of heavy drinkers. Infants of heavy drinkers who had decreased their alcohol consumption during pregnancy had fewer craniofacial features. Infants of heavy smokers were also found to have increased numbers of craniofacial characteristics.

Conclusions-Craniofacial morphology could be a sensitive indicator of alcohol exposure in utero. Altered morphology is usually considered specific for alcohol exposure, but the relation observed with smoking needs further exploration.

Since the first descriptions of the fetal alcohol syndrome in 1968 by Lemoine $e t a l^{1}$ and in 1973 by Jones $e t ~ a l,{ }^{2}$ several hundreds of cases have been described from various countries, all born to alcoholic mothers. It is usually considered that maternal alcoholism is a causal factor for this syndrome, which includes growth retardation, characteristic craniofacial morphology, and impaired mental development. ${ }^{3}$

Partial forms of fetal alcohol syndrome, including one or several of the signs mentioned above, at a more or less severe stage, are less well known. Numerous factors influence morphogenesis, growth and development, and the degree to which more moderate alcohol consumption might be harmful is not clear; nonetheless experimental studies in animals give weight to the hypothesis of a teratogenic role of alcohol in pregnancy, though an embryolethal effect, and effects on congenital malformations, growth, development, and behaviour. ${ }^{4}$

Since craniofacial morphology appears to be most specific for alcohol exposure, the objective of this study was to look at craniofacial characteristics and intrauterine growth at various levels of alcohol consumption. From previous studies $^{56}$ our hypothesis was that no clinical effect of alcohol exposure in utero would be detectable for light or moderate drinking, and that such an effect would appear only for heavy drinkers (not necessarily alcoholics), the expected effect being a minor form of fetal alcohol syndrome, with specific craniofacial characteristics, either isolated or combined with intrauterine growth retardation into features suggestive of fetal alcohol effect.

\section{Methods}

SELECTION OF STUDY SAMPLE

The study population included all women of French origin who had their first contact with the public maternity hospital in Roubaix between 15 May 1985 and 15 January 1986 . Women of foreign origin were excluded, both because their alcohol consumption is usually low and because craniofacial characteristics vary according to ethnic origin. ${ }^{78}$ Among the 782 women satisfying the above criteria, 698 were actually interviewed, the difference being mainly due to refusals or lack of time of the interviewer; 684 were interviewed at their first antenatal visit in hospital, and 14, who had delivered in the hospital during this eight month period but had had no hospital antenatal care, were interviewed during their postnatal stay. This latter group, although interviewed retrospectively, was entered in the study, as it usually includes a high proportion of heavy drinkers and is at high risk of adverse pregnancy outcome. However, we checked that excluding them did not modify the results of the analysis. The interviews were conducted using a structured questionnaire. Separate inquiry was made on the consumption of cider, beer, wine, and stronger 
alcohols, in the number of glasses per day on week days and at weekends. One glass of each beverage was assumed to contain the same quantity of absolute alcohol, an average of $10 \mathrm{~g}$. The hospital is located in an area of higher than average alcohol consumption, and the alcohol consumed in this population is mainly beer.

Women were classified by their average weekly drinking before pregnancy into "light drinkers", consuming 0-6 glasses a week (65\%), "moderate drinkers", 7-20 glasses a week $(16 \%)$, "heavy drinkers", 21 glasses a week or more $(12 \%) ; 7 \%$ of women were identified as known or suspected alcoholics, either by the interviewer, or from the medical record. They were considered as a separate group, independent of the alcohol consumption they had declared, in order to avoid classifying some alcoholics as light or moderate drinkers. A similar classification was used for alcohol consumption during the first trimester. Abstinent women were not considered separately, as most previous studies have not found any difference in outcome between abstinents and light drinkers. ${ }^{56}$

A subsample was selected for a standardised neonatal morphological examination consisting of all alcoholics, all heavy drinkers, and for each such heavy drinker, one light drinker and one moderate drinker matched on the date of recruitment. We selected 347 women by this process; 10 women delivered elsewhere, four had an abortion, and five who had a twin pregnancy were excluded; in two cases, alcohol consumption in the first trimester was unknown; 124 infants were not assessed due to lack of time, early discharge from the hospital or, more rarely, transfer to another unit.

There was no significant difference in the percentage of infants examined according to the level of alcohol consumption: $66 \%$ of the light drinkers' infants, $\mathbf{5 8 \%}$ of the moderate drinkers', $59 \%$ of the heavy drinkers', and $63 \%$ of the alcoholic group. However, the mothers of infants who were examined described an average beer consumption lower than that of the mothers of infants not examined. In this latter group, the infants also tended to have a lower gestational age and birthweight; this trend was observed in all alcohol groups. The final sample for analysis consisted of 202 mother-infant pairs.

Table I Incidence of craniofacial characteristics by drinking group in the first trimester. Values are percent affected

\begin{tabular}{llll}
\hline & $\begin{array}{l}\text { Light and } \\
\text { moderate } \\
\text { drinkers } \\
(\boldsymbol{n}=151)\end{array}$ & $\begin{array}{l}\text { Heavy } \\
\text { drinkers } \\
(\boldsymbol{n}=26)\end{array}$ & $\begin{array}{l}\text { Alcoholics } \\
(\boldsymbol{n}=25)\end{array}$ \\
$\begin{array}{l}\text { Craniofacial } \\
\text { characteristics }\end{array}$ & 40 & 46 & 52 \\
\hline Bulged forehead (profile) & 0 & 0 & 4 \\
Synophris & 13 & 24 & 20 \\
Short palpebral fissures $(\leqslant 18 \mathrm{~mm})$ & 10 & 20 & 24 \\
Antimongoloid slants & 3 & 8 & 4 \\
Strabismus & 5 & 8 & 8 \\
Epicanthic folds & 14 & 15 & 17 \\
Eyelid ptosis & 13 & 12 & 60 \\
Hypertelorism $(\geqslant 24 \mathrm{~mm})$ & 42 & 50 & 60 \\
Deep nasal bridge & 34 & 61 & 12 \\
Upturned nose & 5 & 0 & 12 \\
Short nose & 13 & 11 & 40 \\
Long philtrum $(\geqslant 12 \mathrm{~mm})$ & 5 & 4 & 40 \\
Hypoplastic philtrum & 11 & 27 & 12 \\
Indistinct cupid bow & 49 & 69 & \\
Thin upper lip & 29 & 28 & \\
Retrognathia & 7 & 5 & \\
Posterior rotation of ears $\left(>20^{\circ}\right)$ & & & 4 \\
\hline
\end{tabular}

OUTCOME MEASURES

A standardised morphological examination was administered by one of three paediatricians who had no knowledge of maternal alcohol consumption or any other maternal characteristics; $92 \%$ of examinations were conducted on the first week of life.

A list of 17 craniofacial characteristics described in previous reports on fetal alcohol syndrome ${ }^{9}$ was selected by a paediatrician (PD). Table I shows the frequency of each item by drinking group in the first trimester. The number of craniofacial characteristics was calculated for each infant. Infants were considered to have features compatible with fetal alcohol effects if they had at least four craniofacial characteristics, and if their birthweight, length, or head circumference was below the 10th centile according to sex and gestation, using Largo et al's curves as a reference. ${ }^{10}$

\section{CONFOUNDING VARIABLES}

Very little is known about the relation between maternal characteristics (other than alcohol consumption) and craniofacial characteristics. Thus we have considered as potential confounders the classical risk factors of intrauterine growth retardation or preterm delivery. ${ }^{11}$ Considering the differences in the characteristics of heavy drinkers in different populations, ${ }^{12}$ we selected those which were found significantly associated with alcohol consumption in our sample: age, educational level, weight gain during pregnancy, number of previous pregnancies, previous preterm delivery, and number of cigarettes smoked per day during pregnancy (table II). Among these, three were found to be associated with the number of craniofacial characteristics in the light or moderate drinkers: number of cigarettes per day during pregnancy, number of previous pregnancies, and level of education. These were controlled for in the analysis. Neither gestational age nor age at examination were found to be related to the number of craniofacial anomalies.

\section{ANALYSIS}

For each maternal or neonatal characteristic, the following comparisons have been made: heavy versus light and moderate drinkers, alcoholic versus light and moderate drinkers, and alcoholics versus heavy drinkers. Light and moderate drinkers were grouped together after having verified the assumption that there was no difference in outcome of pregnancy between these two groups.

The analysis was conducted both on the groups defined from alcohol consumption before pregnancy and on those based on alcohol use in the first trimester. Results reported in this paper are limited to alcohol consumption in the first trimester. Nonetheless, in order to see if a reduction in alcohol consumption in the first trimester was associated with differences in neonatal characteristics, further analysis was done on the subsample of women who were heavy drinkers before pregnancy: the women who remained heavy drinkers in the first trimester were compared to those who had become light or moderate drinkers. 
Pearson's $\chi^{2}$ test and one way analysis of variance were used in the univariate comparisons. Mantel Haenszel test and two way analysis of variance with interaction were used in the bivariate analysis, taking smoking status into account. The relation between the number of craniofacial characteristics and indices of growth as dependent variables, and drinking groups and the confounding variables as independent variables, was investigated by multiple regression analysis. Risk of fetal alcohol effect was assessed by the use of logistic regression analysis. Confidence limits for the relative risk of fetal alcohol effect were estimated using the method described by Katz et al. ${ }^{13}$

\section{Results}

Among the 202 studied women, $12 \%$ were included in the alcoholic group. Before pregnancy, heavy drinking was reported by $24 \%$, moderate drinking by $28 \%$, and light drinking by $36 \%$. During the first trimester, these proportions were respectively $13 \%, 28 \%$, and $47 \% ; 45 \%$ of the original heavy drinkers became light or moderate drinkers in the first trimester.

NUMBER OF CRANIOFACIAL CHARACTERISTICS

Offspring of alcoholics and heavy drinkers in the first trimester had significantly more craniofacial characteristics than those of moderate or light drinkers (table III). Children of alcoholics had more characteristics than those of heavy drinkers, but the difference was not significant. The results were the same when we examined the proportion of children having at least four characteristics. However, a two way analysis of variance showed a significant interaction $(p=0.02)$ between alcohol and tobacco (table IV): in heavy smokers, the average number of craniofacial characteristics did not differ between drinking groups; in nonsmokers or light smokers, the number was significantly related to alcohol exposure, even when adjusted for number of previous pregnancies and level of education in a multiple regression.

\section{INTRAUTERINE GROWTH}

Infants of alcoholic women and of heavy drinkers had a shorter gestation than those of moderate and light drinkers, the difference being significant only for the alcoholics (table III). After adjustment for gestational age, there was no significant difference in birth weight, birth length, or head circumference. The trend, however, was for children of alcoholics to be smaller in weight and size. Adjustment for the confounding variables listed above did not modify the results.

Table II Maternal characteristics by drinking group in the first trimester

\begin{tabular}{|c|c|c|c|c|c|c|}
\hline \multirow[b]{2}{*}{ Maternal characteristics } & \multirow{2}{*}{$\begin{array}{l}\text { 1. Light and } \\
\text { moderate } \\
\text { drinkers } \\
(n=151)\end{array}$} & \multirow{2}{*}{$\begin{array}{l}\text { 2. Heavy } \\
\text { drinkers } \\
(n=26)\end{array}$} & \multirow{2}{*}{$\begin{array}{l}\text { 3. Alcoholics } \\
(n=25)\end{array}$} & \multicolumn{3}{|l|}{$p$ value } \\
\hline & & & & $2 \mathrm{v} 1$ & $3 \mathrm{v} 1$ & $3 \times 2$ \\
\hline $\begin{array}{l}\text { Age (years) } \\
\text { Low educational statust }(\%) \\
\text { Weight gain (kg) } \\
\text { One or more previous pregnancies (\%) } \\
\text { Previous preterm delivery }(\%) \\
\text { No of cigarettes/day during pregnancy }(\%)\end{array}$ & $\begin{array}{l}25 \cdot 6(5 \cdot 3) \\
45 \\
11 \cdot 2(5 \cdot 1) \\
68 \\
5\end{array}$ & $\begin{array}{l}27 \cdot 8(5 \cdot 6) \\
58 \\
11 \cdot 9(4 \cdot 9) \\
85 \\
19\end{array}$ & $\begin{array}{l}31 \cdot 0(5 \cdot 6) \\
79 \\
8 \cdot 7(4 \cdot 0) \\
100 \\
20\end{array}$ & $\begin{array}{l}<0.05 \\
\text { NS } \\
\text { NS } \\
\text { NS } \\
<0.01\end{array}$ & $\begin{array}{l}<0.001 \\
<0.01 \\
<0.05 \\
<0.001 \\
<0.01\end{array}$ & $\begin{array}{l}<0.05 \\
<0.01 \\
<0.05 \\
<0.05 \\
\text { NS }\end{array}$ \\
\hline $\begin{array}{l}\text { No of cigarettes/day during pregnancy }(\%) \\
0 \\
1-9 \\
\geqslant 10\end{array}$ & $\begin{array}{l}71 \\
18 \\
11 \\
\end{array}$ & $\begin{array}{l}62 \\
15 \\
23 \\
\end{array}$ & $\begin{array}{r}52 \\
8 \\
40\end{array}$ & NS & $<0.001$ & NS \\
\hline
\end{tabular}

$\star$ Mean (SD)

t Limited to primary school

Table III Number of craniofacial characteristics and growth indices by drinking group in the first trimester

\begin{tabular}{|c|c|c|c|c|c|c|}
\hline \multirow[b]{2}{*}{ Infant characteristics } & \multirow{2}{*}{$\begin{array}{l}\text { 1. Light and } \\
\text { moderate } \\
\text { drinkers } \\
(n=151)\end{array}$} & \multirow{2}{*}{$\begin{array}{l}\text { 2. Heavy } \\
\text { drinkers } \\
(n=26)\end{array}$} & \multirow{2}{*}{$\begin{array}{l}\text { 3. Alcoholics } \\
(n=25)\end{array}$} & \multicolumn{3}{|l|}{$p$ value } \\
\hline & & & & $2 \mathrm{v} 1$ & $3 \mathrm{v} 1$ & $3 \times 2$ \\
\hline $\begin{array}{l}\text { No craniofacial characteristics } \\
\text { No craniofacial characteristics } \geqslant 4(\%) \\
\text { Gestational age (weeks) } \\
\text { Weight }(\mathrm{g})^{\star} \\
\text { Length }(\mathrm{cm})^{\star} \\
\text { Head circumference }(\mathrm{cm})^{\star} \\
\text { At least one growth measurement } \leqslant 10 \text { th centile }(\%) \\
\text { Features suggestive of FAEt }(\%)\end{array}$ & $\begin{array}{l}2.9(1 \cdot 7) \\
31 \\
39 \cdot 9(1 \cdot 4) \\
3301(496) \\
49 \cdot 9(2 \cdot 1) \\
34 \cdot 3(1 \cdot 5) \\
28 \\
7\end{array}$ & $\begin{array}{l}3 \cdot 8(1 \cdot 5) \\
65 \\
39 \cdot 4(1 \cdot 6) \\
3368(525) \\
50 \cdot 0(2 \cdot 4) \\
34 \cdot 6(1 \cdot 3) \\
23 \\
19\end{array}$ & $\begin{array}{l}4 \cdot 3(1 \cdot 9) \\
72 \\
39 \cdot 1(2 \cdot 0) \\
3014(669) \\
48 \cdot 7(2 \cdot 6) \\
33 \cdot 6(1 \cdot 5) \\
40 \\
36\end{array}$ & $\begin{array}{l}<0.01 \\
<0.01 \\
\text { NS } \\
\text { NS } \\
\text { NS } \\
\text { NS } \\
\text { NS } \\
<0.05\end{array}$ & $\begin{array}{l}<0.001 \\
<0.001 \\
<0.05 \\
\text { NS } \\
\text { NS } \\
\text { NS } \\
\text { NS } \\
<0.001\end{array}$ & $\begin{array}{l}\text { NS } \\
\text { NS } \\
\text { NS } \\
\text { NS } \\
\text { NS } \\
\text { NS } \\
\text { NS } \\
\text { NS }\end{array}$ \\
\hline
\end{tabular}

At least one growth measurement $\leqslant 10$ th centile $(\%)$

* Mean (SD)

ॠ Mean (SD)
$+\mathrm{FAE}=$ fetal alcohol effect. At least four craniofacial characteristics and at least one growth measurement below the 10 th centile for gestational age

Table IV Number of craniofacial characteristics by drinking group in the first trimesster and by smoking status during pregnancy. Values are means (SD)

\begin{tabular}{|c|c|c|c|c|c|c|}
\hline & \multirow{2}{*}{$\begin{array}{l}\text { 1. Light and } \\
\text { moderate } \\
\text { drinkers }\end{array}$} & \multirow{2}{*}{$\begin{array}{l}\text { 2. Heavy } \\
\text { drinkers }\end{array}$} & \multirow[b]{2}{*}{ 3. Alcoholics } & \multicolumn{3}{|l|}{ p value } \\
\hline & & & & $2 \mathrm{v} l$ & $3 \mathrm{v} 1$ & $3 \mathrm{v} 2$ \\
\hline $\begin{array}{l}\text { No of cigarettes/day: } \\
0-9 \\
n\end{array}$ & $135^{2 \cdot 8(1 \cdot 7)}$ & $20^{3 \cdot 9(1.4)}$ & $\begin{array}{l}4 \cdot 7(1 \cdot 6) \\
15\end{array}$ & $<0.01$ & $<0.001$ & $(0 \cdot 1)$ \\
\hline $\mathrm{n}^{\geqslant 10}$ & $\begin{array}{l}3.6(1.4) \\
16\end{array}$ & $\begin{array}{l}3.5(1.9) \\
6\end{array}$ & $\begin{array}{l}3 \cdot 6(2 \cdot 1) \\
10^{3}\end{array}$ & NS & NS & NS \\
\hline
\end{tabular}


FEATURES SUGGESTIVE OF FETAL ALCOHOL EFFECT The proportion of children with features suggestive of fetal alcohol effect was significantly higher among heavy drinkers and alcoholic women than among light and moderate drinkers (table III). The relative risk was 5.4 for alcoholics compared to light and moderate drinkers $(95 \%$ confidence interval: $2 \cdot 5-12 \cdot 0$ ), and 2.9 for heavy drinkers (95\% confidence interval: $1 \cdot 1-7 \cdot 8)$.

When controlling for tobacco, number of previous pregnancies, and level of education in a multiple logistic regression, the relative risk of heavy drinkers was only at the limit of significance.

REDUCTION IN ALCOHOL CONSUMPTION IN THE FIRST TRIMESTER

Among the women who were heavy drinkers before pregnancy, there was no difference in growth indices, whether the women had remained heavy drinkers in the first trimester or had become light or moderate drinkers. In contrast, the children in the latter group had fewer $(p<0.05)$ craniofacial characteristics $(2.8)$ than those of the women who had remained heavy drinkers (3.8), and were similar to children of light and moderate drinkers before pregnancy. A similar trend was observed for the proportion of children with features suggestive of fetal alcohol effect.

Although the women who remained heavy drinkers in the first trimester were also more often heavy smokers, these relationships were not explained by tobacco. There was no difference in average prepregnancy alcohol consumption, whether the women remained heavy drinkers or had decreased their alcohol consumption in the first trimester.

FETAL ALCOHOL SYNDROME AND CONGENITAL MALFORMATIONS

After the morphological assessment, two children were diagnosed as having fetal alcohol syndrome by the examiner; the mother of one of them was an alcoholic, whereas the other was a moderate drinker before pregnancy, classified as light drinker in the first trimester. Neither of them showed any other congenital malformation. Congenital malformations were very few in the total sample.

\section{Discussion}

This study has shown that infants of alcoholics and women drinking heavily in the first trimester of pregnancy (three drinks a day or more) on average had more craniofacial characteristics and features compatible with a possible fetal alcohol effect than infants of light and moderate drinkers. A similar relation was found with heavy smoking during pregnancy. An interaction between alcohol and tobacco was observed, the relationship with alcohol exposure being limited to non-smokers or light smokers. However, the proportion of heavy smokers was low in our population.

These results were observed in spite of the fact that the power of the study was limited for two reasons: (1) the group of alcoholics may have included a few more moderate drinkers, thus reducing the contrast in comparison to the other groups of women; however, in this group $38^{\circ}{ }_{0}$ of women had a gamma glutamyl transferase above $18 \mathrm{U} /$ litre, in comparison to $6 \%$ and $18^{\circ}$ o respectively in the two other groups; $;^{14}(2)$ among the subsample selected for morphological examination, $38 \%$ were not examined. In view of the reasons for the absence of assessment, and the organisation of the neonatal examination, there is no reason to suppose that the appearance of the infants may have influenced whether or not they were examined. As heavier drinking and low birthweight were slightly overrepresented among the infants who were not assessed, the study can lead only to an underestimation of the association between alcohol consumption and infant characteristics. This might explain why no significant relationship was found in this subsample between alcohol consumption and birthweight (apart from the trend observed for alcoholic women), whereas such a relationship has been observed in several previous studies. ${ }^{5}$ 15-17

In this study, two infants were diagnosed as having fetal alcohol syndrome. This number is in agreement with a previous prevalence study carried out in the same city, ${ }^{18}$ where the prevalence varied from 1 in 200 to 1 in 700 , according to the degree of severity of the fetal alcohol syndrome. As mentioned earlier, this study was done in an area characterised by a heavy alcohol consumption, and the sampling overrepresented the heavier drinkers.

The significant relationship found between the quantity of alcohol consumed and the number of craniofacial characteristics, either isolated or associated with intrauterine growth retardation, is consistent with the results of the only other study we know of which had a similar approach. ${ }^{8}$ In this study, the authors considered 15 craniofacial anomalies of the newborn baby, nine of which were also considered in our study.

The other epidemiological studies which have described anomalies in relation to alcohol consumption have not separated craniofacial features from other anomalies; they have analysed either the total number of anomalies ${ }^{719-21}$ or an index of characteristics consistent with the fetal alcohol syndrome. ${ }^{192223}$ Even though the results of these studies are difficult to compare because of the differences in the anomalies they have considered, they seem consistent with a nonlinear dose-response relationship. A significant association between anomalies and alcohol was found in studies on alcoholics, or when the level of definition or the proportion of heavier drinkers was high. ${ }^{20-23}$ At lower levels, no significant association was observed. ${ }^{7} 19$

For their score of anomalies, Ernhart et $a l^{8}$ showed a curvilinear dose-response relationship, with a really marked increase above three ounces of alcohol (six drinks) per day. In our study, an increase in the number of craniofacial anomalies was detected for consumption of three drinks a day or more. These results do not rule out a possible effect on craniofacial morphogenesis at lower doses, but this effect might be too small to be clinically detectable.

Our results, as well as those of Ernhart and colleagues, suggest that the effect of alcohol toxicity on craniofacial morphogenesis might be 
mostly linked to first trimester alcohol exposure, as opposed to alcohol consumption before pregnancy. This hypothesis is consistent with experimental studies. ${ }^{24}$ Among heavy drinkers in the first trimester, most must have continued during the whole pregnancy; Rosett et $a l^{20}$ have found that children of heavy drinkers had more anomalies than children of moderate drinkers, whether or not they had modified their alcohol consumption later in pregnancy.

In this study, craniofacial characteristics were more numerous among infants of heavy smokers in pregnancy. Although features compatible with fetal alcohol effects have been observed in marijuana users in one study, ${ }^{19}$ the association with tobacco has never been found. ${ }^{719-22} 25$ Even though a few associations with congenital defects have been observed, tobacco is not generally considered to be a teratogen. ${ }^{46}$ It should be noted, however, that a recent paper $^{27}$ has suggested the possibility of identifying maternal smoking through fetal appearance. As the craniofacial characteristics analysed in this study are commonly considered as specific of prenatal alcohol exposure, more investigations on the association with smoking are needed: tobacco is a well known factor causing intrauterine growth retardation, and as with alcohol, might play a role in craniofacial morphogenesis. However, neither this study nor other published reports have considered the craniofacial morphology of the parents as a potential confounding variable.

Features compatible with fetal alcohol effects observed at birth seem to be a good predictor of dysmorphology evaluated at four years of age. ${ }^{25}$ The results of the Seattle follow up study ${ }^{28}$ are in favour of a relationship between intrauterine alcohol exposure and later development, but the value of a specific craniofacial morphology as an indicator of future mental development remains largely unknown. Nonetheless, this study, as well as that of Ernhart et $a l^{\mathbf{2 1}}$ suggests that craniofacial morphology could be a more sensitive and specific indicator of prenatal alcohol effect than other anomalies, growth indices, or neonatal behaviour: the number of craniofacial anomalies could be a useful outcome measure in evaluating the effectiveness of interventions aiming at reducing the alcohol consumption of pregnant heavy drinkers.

We thank A Erramdani, S Hebbinckuys-Ovlaque, $O$ Klein, and D Subtil for their contribution to the data collection; A Hennion and M Franczuk for their technical assistance in the extraction of data from the computerised hospital records; the staff of the Obstetric Department for their help and support; and all the pregnant women who have participated in the study. The data were analysed at the INSERM computer centre SC5, and the manuscript was prepared with the assistance of $M$ Corre.

The stuciy is part of the EC Concerted Action: "Maternal alcohol consumption and its effect on pregnancy and child development". The study was partly funded by the Haut Comite d'Etudes et d'Information sur l'Alcoolisme (re 1984/63). Agnès Rostand was supported by a grant from the Fondation pour la Recherche Médicale.
1 Lemoine P, Harousseau H, Borteyru JP, Menuet JC. Les enfants de parents alcooliques: anomalies observ́ees. Ouest Médical 1968; 21: 476-82.

2 Jones KL, Smith DW, Ulleland CN, Streissguth AP. Pattern of malformation in offspring of chronic alcoholic mothers. Lancet 1973; i: 1267-71.

3 Rosett HL. A clinical perspective of the fetal alcohol syndrome. Alcoholism Clin Exp Res 1980; 4: 119-22.

4 Abel EL. Consumption of alcohol during pregnancy: a review of effects on growth and development of offspring. Human Biol 1982: 54: 421-53.

5 Kaminski M, Rumeau-Rouquette C, Schwartz D. Consommation d'alcool chez les femmes enceintes et issue de la grossesse. Rev Epidemiol Santé Publique 1976; 24: $27-40$.

6 Kaminski M, Franc M, Lebouvier M, du Mazaubrun C, Rumeau-Rouquette C. Moderate alcohol use and pregnancy outcome. Neurobehav Toxicol Teratol 1981; 3: $173-81$

7 Tennes $\mathrm{K}$, Blackard C. Maternal alcohol consumption, birthweight, and minor physical anomalies. $\mathrm{Am} \mathcal{F}$ Obstet Gynecol 1980; 138: 774-80.

8 Ernhart CB, Sokol RJ, Martier S, et al. Alcohol teratogenicity in the human: a detailed assessment of specificity, critical period, and threshold. Am $\mathcal{F}$ Obstet Gynecol 1987; 156: 33-9.

9 Clarren SK, Smith DW. The fetal alcohol syndrome. N Eng f Med 1978; 298: 1063-7.

10 Largo RH, Walli R, Duc G, Fanconi A, Prader A. Evaluation of perinatal growth. Helv Paediatr Acta 1980; 35: 419-36.

11 Thomson AM. Fetal growth and size at birth. In: Barron SL, Thomson AM, eds. Obstetrical epidemiology. London: Academic Press, 1983: 89-142.

12 Walpole I, Zubrick S, Pontré J. Confounding variables in studying effects of maternal alcohol consumption before and during pregnancy. $\mathcal{F}$ Epidemiol Community Health 1989; 43: 153-61.

13 Katz D, Baptista J, Azen SP, Pike MC. Obtaining confidence intervals for the risk ratio in cohort studies. Biometrics 1978; 34: 469-74.

14 Kaminski M, Rostand A, Lelong N, et al. Consommation d'alcool pendant la grossesse et caractéristiques néonatales. Journal d'Alcoologie 1989; 1: 35-46.

15 Little RE. Moderate alcohol use during pregnancy and decreased infant birthweight. Am $\mathcal{F}$ Public Health 1977; 67: $1154-6$.

16 Wright JT, Waterson EJ, Barrison IG, et al. Alcohol consumption, pregnancy, and low birthweight. Lancet 1983; i: 663-5.

17 Mills JL, Graubard BI, Harley EE, Rhoads GG, Berendes $\mathrm{HW}$. Maternal alcohol consumption and birth weight. How mW. Maternal alcohol consumption and birth weight. How much drin

18 Dehaene P, Crepin G, Delahousse G, et al. Aspects épidémiologiques du syndrome d'alcoolisme foetal. Nouvelle Presse Médicale 1981; 10: 2639-43.

19 Hingson R, Alpert JJ, Day N, et al. Effects of maternal drinking and marijuana use on fetal growth and development. Pediatrics 1981; 70: 539-46.

20 Rosett HL, Weiner L, Lee A, Zuckerman B, Dooling E, Oppenheimer E. Patterns of alcohol consumption and fetal Oppenheimer E. Patterns of alcohol consumption

21 Ernhart CB, Wolf AW, Linn PL, Sokol RJ, Kennard MJ, Filipovich HF. Alcohol-related birth defects: syndromal anomalies, intrauterine growth retardation, and neonatal behavioral assessment. Alcoholism Clin Exp Res 1985; 9 . 447-53.

22 Hanson JW, Streissguth AP, Smith DW. The effects of moderate alcohol consumption during pregnancy on fetal growth and morphogenesis. Pediatrics 1978; 92: 457-60.

23 Silva VA, Laranjeira RR, Dolnikoff M, Grinfeld H, Masur $\mathrm{J}$. Alcohol consumption during pregnancy and newborn J. Alcohol consumption during pregnancy and newborn 1981; 3: 169-72.

24 Pratt OE. What do we know of the mechanisms of alcohol damage in utero? In: Mechanisms of alcohol damage in utero. (CIBA Foundation Symposium No 105) London: Pitman, 1984: 1-7.

25 Graham JM, Hanson JW, Darby BL, Barr HM, Streissguth AP. Independent dysmorphology evaluations at birth and four years of age for children exposed to varying amounts of four years of age for children exposed t7 vis.

26 Shiono PH, Klebanoff MA, Berendes HW. Congenital malformations and maternal smoking during pregnancy. malformations and materna

27 Stirling HF, Handley JE, Hobbs AW. Passive smoking in utero: its effects on neonatal appearance. $\mathrm{Br} M e d \mathcal{F} 1987$; 295: 627-8.

28 Streissguth AP, Barr HM, Martin DC. Alcohol exposure in utero and fonctional deficits in children during the first four years of life. In: Mechanisms of alcohol damage in utero. (CIBA Foundation Symposium No 105) London: Pitman, 1984: 176-96. 